\title{
Edótoríal
}

\section{AVITAMINOSIS AND THE NERVOUS SYSTEM}

$T^{T}$ is almost forty years since Eijkman, the medical officer of a Javanese prison where beriberi was rampant, observed that fowls feeding on refuse rice developed paralytic symptoms like those of his patients, and showed that pigeons fed on polished or decorticated rice were attacked whereas others eating the whole grain continued immune. Some essential food factor, thought by him to be protein and phosphorus, evidently disappeared when rice was submitted to a shelling process. The identity of this 'polyneuritis gallinarum' with human beriberi was assumed. In 1907 Holst proved that the deficiency could not be one of protein by quoting an outbreak among Norwegian sailors enjoying a diet rich in meat. To Funk (1911) is due credit for the preparation from rice polishings of a crystalline substance having a pronounced curative effect on avian polyneuritis. From these days the lore of avitaminosis has steadily been incremented; the word 'vitamin' has become popular as a term for a mysterious substance that has a miraculous effect; and the profession, captivated by the same notion, is now seeking an explanation for a variety of nervous symptoms and diseases in the negative factor of absence of something. That this way scientific danger lies can hardly be gainsaid.

So long ago as 1912, when at a medical society meeting Funk claimed, and indeed showed, that the paralysis of pigeons fed on hulled rice could be made to disappear in an hour or two by the simple addition of whole rice, the criticism was advanced that whatever this paralysis was, it could not possibly be due to a polyneuritis in the sense of the neurologist. It must rather have been a dynamic defect or cessation of function due perhaps to some kind of cell starvation. Since that date, a number of studies have culminated in the view that so far as this alleged polyneuritis of pigeons is concerned only the acute symptoms can be made to disappear dramatically by injection of extract of rice polishings, and these acute symptoms are not those of any kind of neuritis. On the contrary, they are rather of the 
nature of tonic spasms and so-called vestibular fits, for which an origin in mesencephalon or brainstem-as in a decerebrate animal-is much the most likely. Other studies have finally led to the isolation of the substance prepared by Funk, which is now named the ' antineuritic' factor vitamin $\mathbf{B}_{1}$. According to Peters its formula (or rather that of its hydrochloride) is $\left(\mathrm{C}_{12} \mathrm{H}_{1 ;} \mathrm{ON}_{4} \mathrm{~S} . \mathrm{HCl}\right) \mathrm{Cl}$. A daily dose of $0.002 \mathrm{mgm}$. $(2 \cdot 0 \gamma)-$ constituting the international vitamin $B_{1}$ unit-will cure pigeons suffering from experimental 'polyneuritis.' Peters and his colleagues have shown, by a series of fine researches, that the rôle of the vitamin concerned is to help in oxidizing certain carbohydrate intermediates (notably lactic and pyruvic acids) found principally in the brainstem; it is a catalyst whose absence will interfere with the metabolism of glucose, failure in the development of energy from sugars stopping the normal activity of various central groups of nerve-cells. If this is so, if the 'biochemical lesions' of vitamin $\mathbf{B}_{1}$ deficiency are in reality pontobulbar, then the inference would be that the acute and reversible symptoms of avian 'polyneuritis' are in reality of central origin ; a supply of $B_{1}$ will remove pyruvates and quickly restore tissue respiration. But it must be equally clear that the experimental data do not account for the fact that the symptoms and lesions of beriberi are in essence neuritic ; why and in what way impeded carbohydrate metabolism should affect peripheral nerves, as contrasted with nerve-cells of the brainstem, does not appear, and has not been explained. Through all Peters' experiments the action of the morbid process is seen to be on nerve-cells, whereas in human beriberi these are scarcely changed, the maximum effect falling on distal peripheral nerves. Again, various efforts to reproduce ' neuritis ' by feeding rats and other animals on a dietary lacking the 'antineuritic' substance' $B_{1}$ have been extraordinarily inconclusive. In spite of these and other reasons for suspending judgment, we note an increasing tendency nowadays to ascribe other forms of neuritis not to a specific (or unspecific) poison but to inadequate supply of vitamin $B$ complex; this has been asserted in regard to the alcoholic variety, that of pregnancy, and others still. Some writers go to the absurd extreme of alleging that these kinds of neuritis, and beriberi, are one and the same disease, ignoring the self-evident difficulties of such a claim-for instance, the geographical factor is overlooked. As Aykroyd asks, why should a wretched diet of milled cereals lead to pellagra in South Carolina, to beriberi in Java and Newfoundland, and to scurvy 
on the Rand ? And we may ask, too, on general lines, what is the precise causal connexion between vitamin and disease? Does the latter spring into being as soon as ever the former fails, without the action of any intervening process? Were this so, the observed fact that only a proportion of those persons whose food is insufficient develop symptoms becomes incomprehensible; in an Egyptian native family, for example, there may be, indeed very frequently is, one solitary pellagrin, yet all the other members are eating the same food, drinking the same drink, living in the same surroundings, having the same agricultural occupation. In the case of rickets there is good reason to believe that the relation between vitamin and disease is far from simple, and data advanced above show this to be true (mutatis mutandis) of beriberi.

Another rather curious circumstance is the consiancy with which 'cures' are vaunted for proof of the hypothesis that lack of a foodstuff per se is responsible for all the phenomena, clinical and pathological. This claim is always being put forward, e.g. by those who think that the neuritis of pregnancy or of alcohol is due to shortage of the 'antineuritic' factor. There is no notion here of the possible function of vitamin as a shielding or defensive substance, in the absence of which some noxa runs riot. Yet cogent evidence might be adduced to suggest that the purpose of vitamin in the organism is prophylactic. The idea that ' naturam morborum curationes ostendunt' is an old fallacy, and it is odd to find it cropping up once more in connexion with avitaminosis. Were it correct, then the fact that hysterical syndromes can be removed (say) by priestcraft and by psychoanalysis alike must signify that the psychoneurosis is due to demoniacal possession as well as to an abnormal vita sexualis.

The position at present in respect of avitaminosis seems to be, that the complexity of the pathogenic factors is being ignored in some quarters, and that a false simplicity has been introduced by use of such unfortunate terms as ' antirachitic', ' antineuritic', ' antixerophthalmic ' and other ' anti 'vitamins, as though there were specific vitamins for specific diseases. The number of the former is doubtless slowly increasing, but their rôle in pathogenesis has yet to emerge in complete and definite form. 